\title{
TAMANHO DA SUBAMOSTRA E REPRESENTATIVIDADE DA FERTILIDADE DO SOLO NO SISTEMA PLANTIO DIRETO ${ }^{1}$
}

\author{
SUBSAMPLE SIZE AND SOIL FERTILITY REPRESENTATIVITY \\ IN THE NO TILLAGE SYSTEM
}

\author{
Jairo André Schlindwein ${ }^{2}$ Ibanor Anghinoni ${ }^{3}$
}

\section{RESUMO}

Os corretivos e fertilizantes, quando aplicados de forma localizada, mantêm-se ao longo das linhas de cultivo no sistema plantio direto. Isto se reflete no aumento da variabilidade horizontal dos atributos químicos do solo, causando dificuldades para a coleta de amostras representativas do seu estado de fertilidade. Este trabalho foi desenvolvido em dois estudos, em solos cultivados no sistema plantio direto. O primeiro foi com objetivo de relacionar o tamanho da amostra e a variabilidade de fósforo e potássio disponíveis. Para isto, amostrouse o solo de um experimento e de uma lavoura, em diferentes tamanhos de subamostras e camadas, em Latossolo Vermelho com adubação a lanço. $O$ segundo estudo foi conduzido para testar a eficiência de equipamentos de amostragem com diferentes tamanhos, através da variabilidade dos atributos de fertilidade do solo e o seu efeito no número de subamostras para compor uma amostra composta, dentro de determinados limites de precisão. Para isto, amostraram-se duas lavouras em Latossolo Vermelho, na profundidade de $0-10 \mathrm{~cm}$, com trado de rosca e pá de corte; esta no tamanho de $5 / 10 \mathrm{~cm}$ (espessura/largura) na lavoura de adubação a lanço e $5 \mathrm{~cm}$ pela largura da entrelinha na lavoura de adubação em linha. As amostras retiradas com trado de rosca apresentaram menores teores de matéria orgânica e potássio disponível na lavoura de adubação em linha e de fósforo disponível em ambos os modos de adubação. Nesta situação, também ocorreu maior variabilidade e, consequentemente, necessidade de coletar um maior número de subamostras para representar o estado de fertilidade no sistema plantio direto. Amostras com $5 / 10 \mathrm{~cm}$ (espessura/largura), foram eficientes para representar o estado de fertilidade do solo com adubação a lanço no sistema plantio direto.

Palavra-chave: formas de adubação, variabilidade horizontal, número de subamostras.

\section{SUMMARY}

Fertilizers and lime, when applieds on surface to soil or along crop rows in the no tillage system, increase its residual effect. This results in an increase in the horizontal variability of the soil chemical characteristics, and in difficulties for collecting representative soil fertility samples. This research was carried out in two studies: the first one was to relate the subsample size with variability of the available phosphorus and potassium. Soil samples were collected with a shovel in an experiment and in a crop fild area in the no tillage system broadcast fertilized, at different sizes and layers up to $20 \mathrm{~cm}$ depth. The second study was conducted to test the efficiency of different sizes and shapes of subsamples, given by soil sample equipments, througth the variability of soil fertility indexes. Two crop field areass under no tillage system were sampled at the 0 $10 \mathrm{~cm}$ depth with a screw auger and with a shovel with $5 / 10 \mathrm{~cm}$ (thickness/wideness) in the broadcast fertilizer field, and with $5 \mathrm{~cm}$ thick and inter-row width in the row fertilized field. When the soil was sampled with the screw auger, the soil organic matter and available potassium content was lower in the row fertilized field, and available phosphorus content was lower in both, broadcast and row fertilized fields. In this situation, the variability was higher and, as a consequence, a higher number of subsamples were required to represent the fertility status of the soil. Soil samples taken with the shovel at the $5 / 10 \mathrm{~cm}$ size were efficient to represent the soil fertility when the soil was broadcast fertilized in the no tillage system.

Key words: fertilizer placement, horizontal variability, number of subsamples.

\footnotetext{
${ }^{1}$ Parte do trabalho apresentado na forma de resumos na XXIII Reunião Brasileira de Fertilidade do Solo e Nutrição de Plantas, VII Reunião Brasileira sobre Micorrizas, V Simpósio Brasileiro sobre Microbiologia do Solo, II Reunião Brasileira de Biologia do Solo, Caxambu, MG, 1998 e Resumos expandidos na II Reunião Sul-Brasileira de Ciência do Solo, Santa Maria, RS, 1998. Financiado pela FAPERGS e FINEP/PRONEX.

${ }^{2}$ Engenheiro Agrônomo MSc., Aluno de Doutorado do Programa de Pós-graduação em Ciência do Solo, Universidade Federal do Rio Grande do Sul (UFRGS). Avenida Bento Gonçalves, 7712, CP 776, 90001-970, Porto Alegre, RS. E-mail: jairojas@vortex.ufrgs.br. Autor para correspondência.

${ }^{3}$ Professor Adjunto da Faculdade de Agronomia da UFRGS. Bolsista do CNPq.
} 


\section{INTRODUÇÃO}

O problema na representatividade de amostras de solo para determinar o estado de fertilidade está na desuniformidade espacial dos atributos químicos, conhecida como variabilidade do solo. Esta variabilidade pode ser atribuída a causas naturais, pelo efeito de fatores de formação do solo sobre o material de origem (maiores distâncias) e pela ação antrópica na atividade agrícola (menores distâncias). JAMES \& WELLS (1990) caracterizam a variabilidade horizontal do solo resultante da aplicação de fertilizantes em três tipos: as microvariações, que ocorrem em distâncias entre 0 a $0,05 \mathrm{~m}$, são devido ao local (sítio) onde o fertilizante é colocado no solo; as mesovariações, que ocorrem em distâncias entre 0,05 a $2 \mathrm{~m}$, são devido às adubações em linha e as macrovariações são para distâncias maiores que $2 \mathrm{~m}$. Assim, para contemplar a variabilidade horizontal do solo e ter uma boa representatividade do seu estado de fertilidade, o número de subamostras devem contemplar as macrovariações, enquanto a forma, o tamanho e o local de amostragem devem contemplar as micro e as mesovariações.

No sistema convencional de cultivo, a maioria dos Programas de Adubação e de Calagem, elaborados regionalmente no Brasil, recomendam indistintamente o uso do calador (sonda), trado de rosca, trado holandês ou pá de corte, utilizando, neste último, a parte central, o que resulta em subamostras de pequeno volume. Nesse sistema de cultivo, o revolvimento constante do solo provoca uma homogeneização na camada mobilizada. Isto não ocorre no sistema plantio direto, que mantém o efeito residual prolongado dos fertilizantes acumulados na superfície do solo (ELTZ et al., 1989) e nas linhas de cultivo (JAMES \& WELLS, 1990; KLEPKER \& ANGHINONI, 1993, 1995; KRAY et al., 1997), aumentando a variabilidade do solo, tanto no sentido horizontal como vertical em relação ao sistema convencional de cultivo (SOUZA, 1992; SALET et al., 1996). Resta saber se os equipamentos utilizados no sistema convencional e se o tamanho das subamostras coletadas são apropriados para contemplar a variabilidade do solo no sistema plantio direto.

A magnitude do efeito residual de corretivos e fertilizantes depende do tipo, da freqüência e da quantidade aplicada. É, também, maior para aqueles elementos de menor mobilidade no solo, como, por exemplo, o fósforo, seguido pelo potássio. A matéria orgânica, o pH em água e o índice SMP apresentam variabilidade bem mais baixa (SCHLINDWEIN \& ANGHINONI, 2000).
Neste trabalho, realizaram-se dois estudos em áreas de plantio direto: o primeiro, com o objetivo de definir a relação entre o tamanho de subamostra e a variabilidade do solo, e o segundo, com o objetivo de verificar a eficiência de equipamentos de coleta de amostras de solo em representar o seu estado de fertilidade, através do número de subamostras.

\section{MATERIAL E MÉTODOS}

No primeiro estudo, amostras de solo foram retiradas em maio de 1997, de um Latossolo Vermelho Distróférrico típico de um experimento conduzido por três anos no sistema plantio direto, adubado na dose recomendada pela COMISSÃO... (1995), sempre a lanço, localizado na Embrapa Trigo, em Passo Fundo-RS. O experimento foi cultivado com a rotação de culturas trigo/soja/aveia preta + ervilhaca/milho/aveia branca/soja (Triticum aestivum/Glycine max/Avena strigosa + Vicia sativa/Zea may/Avena sativa/Glycine max). As amostras de solo de dois locais (sítios) foram retiradas com pá de corte, nos tamanhos 2,5/5; 5/5 e $5 / 10 \mathrm{~cm}$, (espessura/largura) e nas profundidades de $0-2,5 ; 2,5-5 ; 5-7,5 ; 7,5-10 ; 10-12,5 ; 12,5-15 ; 15-$ 17,$5 ; 17,5-20 ; 0-5 ; 0-10 ; 0-15$ e $0-20 \mathrm{~cm}$.

Amostras de solo também foram retiradas, em novembro de 1997, em uma lavoura de um Latossolo Vermelho Distroférrico típico, cultivada por nove anos no sistema plantio direto, com rotação trigo/soja/aveia preta + ervilhaca/milho/nabo forrageiro (Raphanus sativus)/soja, com adubações sempre a lanço, nas doses recomendadas pela COMISSÃO...(1995), localizada no município de Coronel Bicaco-RS. As amostras de 10 locais (sítios) foram coletadas aleatoriamente em área de aproximadamente quatro ha, na camada de $0-10 \mathrm{~cm}$ de profundidade e tamanhos de 2,5/2,5; 5/5; 5/10 e 10/10cm, (espessura/largura). As amostras das duas áreas foram secas e analisadas em duplicata, para fósforo e potássio disponíveis (Mehlich-I), conforme procedimentos descritos em TEDESCO $\boldsymbol{e t} \boldsymbol{a l}$. (1995).

No segundo estudo, amostras de Latossolo Vermelho Distroférrico típico foram retiradas, em novembro de 1997, de duas lavouras comerciais cultivadas no sistema plantio direto: uma localizada no município de Coronel Bicaco-RS (descrita acima) e a outra cultivada por 12 anos, com rotação trigo/soja/aveia preta + ervilhaca/ milho/aveia preta/soja, com adubações sempre em linha, nas doses recomendadas pela COMISSÃO... (1995), localizada no município de Santo Augusto RS.

Ciência Rural, v. 32, n. 6, 2002. 
Amostras simples foram retiradas com pá de corte e trado de rosca, em 36 pontos na camada de $0-10 \mathrm{~cm}$ de profundidade, distribuídos uniformemente em área homogênea de aproximadamente quatro ha de cada lavoura. $\mathrm{Na}$ área de adubação em linha, as amostras com pá de corte foram retiradas na largura das linhas do último cultivo (milho a $80 \mathrm{~cm}$ ), de maneira que a linha ficasse centralizada na fatia amostrada (COMISSÃO..., 1995), enquanto as amostras com trado de rosca foram de 5 a $10 \mathrm{~cm}$ de distância da linha de cultivo. $\mathrm{Na}$ área de adubação a lanço, as amostras foram retiradas independentemente das linhas de cultivo, com trado de rosca e pá de corte no tamanho $5 / 10 \mathrm{~cm}$.

Analisou-se, em duplicata, o pH em água 1:1, o índice SMP para a indicação da necessidade de calcário, os teores de fósforo e potássio extraídos por Mehlich-I e de matéria orgânica por oxidação com solução sulfocrômica, conforme procedimento descrito por TEDESCO et al. (1995).

Para determinar o número de subamostras, utilizou-se a fórmula :

$$
\mathrm{n}=\left[\left(\mathrm{t}_{\alpha} \times \mathrm{CV}\right) / \mathrm{e}\right]^{2}
$$

onde: n é o número de subamostras a ser coletado; $\mathrm{CV}$ é o coeficiente de variação; $t$ é o valor da tabela (teste t) correspondente ao erro; $\alpha$ e ao número de graus de liberdade do quadrado médio residual e; $e$ é $\mathrm{o}$ erro em torno da média. $\mathrm{O} \mathrm{CV}$ foi calculado a partir das 36 amostras simples, no teste t usou-se $\alpha=$ 0,05 de intervalo de confiança e para o e, usaram-se 10 e $20 \%$ de erro em torno da média.

\section{RESULTADOS E DISCUSSÃO}

O coeficiente de variação dos teores de fósforo e potássio disponíveis no solo diminuiu com o aumento no tamanho das subamostras, tanto na área do experimento (Figura 1-a) como na lavoura (Figura 1-b), ambos cultivados no sistema plantio direto (Estudo 1). De uma maneira geral, não se observou diminuição substancial na variabilidade do solo com o aumento do tamanho da subamostra a partir de $5 / 10 \mathrm{~cm}$. O tamanho de subamostra equivalente ao tamanho do trado de rosca ou calador $(2,5 / 2,5 \mathrm{~cm})$ ou ainda trado holandês $(2,5 / 5 \mathrm{~cm})$ resultou em uma variabilidade elevada dos valores analisados. A maior variabilidade $(\mathrm{CV})$ ocorreu para fósforo disponível na lavoura (Figura 1-b) cultivada por um longo período (nove anos) no sistema plantio direto. Trata-se de um nutriente pouco móvel no solo e decorre das microvariações (menores que $5 \mathrm{~cm}$ de distância) (JAMES \& WELLS, 1990).
O pH em água e o índice SMP (Tabela 1) não foram afetados pela forma de adubação e equipamentos de coleta de amostras do solo (Estudo 2). Os teores de fósforo disponível foram em torno de $30 \%$ menores, nas amostras retiradas com trado de rosca em relação às retiradas com pá de corte, em ambos os modos de adubação. Isto se deve às perdas de solo da camada superficial no momento da amostragem, justamente onde as concentrações de nutrientes e matéria orgânica são maiores (ELTZ et al., 1989).

Na adubação a lanço, a matéria orgânica e o potássio disponível não apresentaram diferenças nos teores em função do equipamento de amostragem (Tabela 1). Porém, na adubação em linha, as amostras retiradas com trado de rosca apresentaram menores teores do que quando as amostras foram retiradas com pá de corte. Para a matéria orgânica, isto se deve à perda de solo na amostragem com trado, da camada superficial mais rica (ELTZ et al., 1989) e, para o potássio, além das perdas da camada superficial, também pode ocorrer maior concentração do nutriente junto às linhas de semeadura das plantas, (KLEPKER \& ANGHINONI, 1995), não contemplada pelo pequeno tamanho da amostra retirada com trado de rosca.

A variabilidade horizontal (Tabela 2) foi maior para fósforo e potássio disponíveis do que para matéria orgânica, $\mathrm{pH}$ em água e índice SMP, como observado também por SOUZA (1992), SALET et al. (1996), SANTOS \& VASCONCELLOS (1987) e SCHLINDWEIN \& ANGHINONI (2000). Os adubos fosfatados e potássicos são aplicados a cada cultivo e provocam maior variabilidade pela localização dos fertilizantes nas linhas de semeadura, que se mantêm através dos cultivos (JAMES \& WELLS, 1990; KLEPKER \& ANGHINONI, 1993, 1995; KRAY et al., 1997).

As amostras retiradas com pá de corte apresentaram variabilidade semelhante, tanto para fósforo como para potássio, em ambos os modos de adubação, e mais baixa do que as amostras retiradas com trado de rosca, para fósforo, em ambos os modos de adubação e para potássio, na adubação em linha (Tabela 2). Isto demonstra que o tamanho da subamostra, diferenciada entre os modos de adubação, com $5 / 10 \mathrm{~cm}$ (espessura/largura) determinado no Estudo 1, para a adubação a lanço e, $5 \mathrm{~cm}$ pela largura da linha do último cultivo, quando a adubação foi feita nas linhas de cultivo (COMISSÃO..., 1995), contempla as micro e mesovariações, características do efeito imediato e residual de 


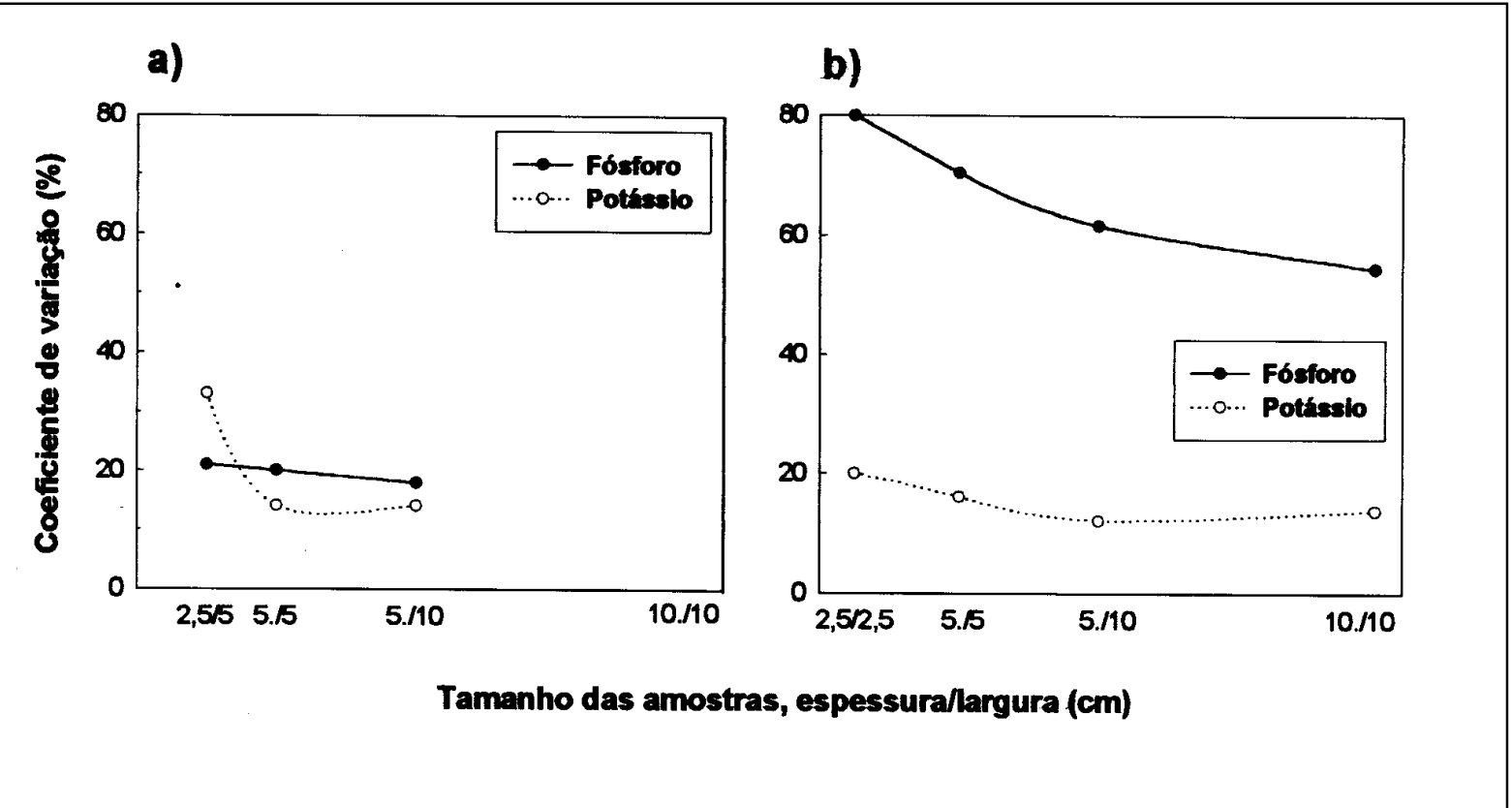

Figura 1 - Coeficiente de variação de fósforo e potássio disponíveis (Mehlich-I) em diferentes tamanhos de subamostras de Latossolo Vermelho Distrófico, cultivado no sistema plantio direto e adubação a lanço. a) média de doze camadas de uma área experimental de três anos, e; b) média de dez amostras da camada de $0-10 \mathrm{~cm}$ de uma lavoura de nove anos.

Tabela 1 - Valores médios dos atributos de fertilidade de um Latossolo Vermelho Distroférrico, amostrado com diferentes equipamentos em lavouras comerciais do sistema plantio direto, em diferentes modos de adubação.

\begin{tabular}{|c|c|c|c|c|c|}
\hline \multirow{2}{*}{$\begin{array}{l}\text { Instrumento } \\
\text { coleta }\end{array}$} & \multirow{2}{*}{$\begin{array}{c}\mathrm{pH} \\
\text { água }\end{array}$} & \multirow{2}{*}{$\begin{array}{l}\text { Índice } \\
\text { SMP }\end{array}$} & \multicolumn{2}{|c|}{ Mehlich-I } & \multirow{2}{*}{$\begin{array}{l}\text { Matéria } \\
\text { Orgânica }\end{array}$} \\
\hline & & & $\mathrm{P}$ & $\mathrm{K}$ & \\
\hline & & & \multicolumn{2}{|c|}{$\mathrm{mg} \mathrm{kg}^{-1}$} & $\mathrm{G} \mathrm{kg}^{-1}$ \\
\hline \multicolumn{6}{|c|}{ Adubação a lanço ${ }^{1}$} \\
\hline Pá de corte & $5,0 \mathrm{a}$ & $5,5 \mathrm{a}$ & $36,4 \mathrm{a}$ & 233 & $42 \mathrm{a}$ \\
\hline Trado de rosca & $5,0 \mathrm{a}$ & $5,5 \mathrm{a}$ & $25,7 \mathrm{~b}$ & $248 \mathrm{a}$ & $41 \mathrm{a}$ \\
\hline \multicolumn{6}{|c|}{ Adubação em linha ${ }^{2}$} \\
\hline Pá de corte & $4,7 \mathrm{a}$ & $5,3 \mathrm{a}$ & $38,0 \mathrm{a}$ & $221 \mathrm{a}$ & $60 \mathrm{a}$ \\
\hline Trado de rosca & $4,5 \mathrm{a}$ & $5,2 \mathrm{a}$ & $25,6 \mathrm{~b}$ & $175 b$ & $38 \mathrm{~b}$ \\
\hline
\end{tabular}

${ }^{1}$ Sistema plantio direto com nove anos de cultivo. ${ }^{2}$ Sistema plantio direto com doze anos de cultivo. Valores seguidos de letras distintas diferem pelo teste Tukey a $5 \%$.

fertilizantes aplicados em linha (JAMES \& WELLS, 1990; KLEPKER \& ANGHINONI, 1993, 1995; KRAY et al., 1997).

Independentemente dos limites de precisão adotados ( $\alpha$ e $e$, da fórmula 1$)$, o número de subamostras necessárias para compor uma amostra representativa (Tabela 3) foi pequeno para $\mathrm{pH}$ em água, índice SMP e matéria orgânica, que apresentam baixa variabilidade no solo, e grande para fósforo e potássio disponíveis que possuem grande variabilidade (Tabela 2). Resultados semelhantes também foram encontrados por SOUZA (1992), SALET et al. (1996), SANTOS \& VASCONCELLOS (1987) e SCHLINDWEIN \& ANGHINONI (2000).

Para $\mathrm{pH}$ em água, índice SMP e matéria orgânica, o número de subamostras foi também, pequeno, independentemente do equipamento de amostragem. Para fósforo e potássio disponíveis, o número de subamostras, para um mesmo limite de precisão, foi maior e dependente do equipamento de amostragem e do modo de adubação: foi maior na coleta com trado de rosca e adubação em linha (Tabela 3).

Para o fósforo disponível, o atributo de fertilidade do solo de maior variação, a amostragem com trado de rosca, além de apresentar menores teores, requer um número de subamostras muito grande, quando se admite um menor erro (10\%) em relação à média: 183 e 92 para a adubação em linha e a lanço, respectivamente e, consideravelmente menor para probabilidade de erro de 20\%: 46 e 23 para a adubação em linha e a lanço, respectivamente. Nas amostras coletadas com pá de corte, o número de subamostras para representar o estado de disponibilidade de fósforo, dentro de um mesmo limite de precisão, independe do modo de adubação: 11 e em torno de 44 para fósforo e 3 e 13 para 
Tabela 2 - Coeficiente de variação de atributos de fertilidade de Latossolo Vermelho Distroférrico, amostrado com diferentes equipamentos em lavouras comerciais no sistema plantio direto em diferentes modos de adubação.

\begin{tabular}{|c|c|c|c|c|c|}
\hline \multirow{2}{*}{$\begin{array}{l}\text { Instrumento de } \\
\text { coleta }\end{array}$} & \multirow{2}{*}{ pH água } & \multirow{2}{*}{$\begin{array}{l}\text { Índice } \\
\text { SMP }\end{array}$} & \multicolumn{2}{|c|}{ Mehlich-I } & \multirow{2}{*}{$\begin{array}{l}\text { Matéria } \\
\text { orgânica }\end{array}$} \\
\hline & & & $\mathrm{P}$ & $\mathrm{K}$ & \\
\hline & \multicolumn{5}{|c|}{ 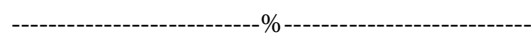 } \\
\hline \multicolumn{6}{|c|}{ Adubação a lanço ${ }^{1}$} \\
\hline Pá de corte & 5,8 & 2,7 & 33,0 & 18,0 & 13,4 \\
\hline Trado de rosca & 6,0 & 3,5 & 47,3 & 21,5 & 14.7 \\
\hline \multicolumn{6}{|c|}{ Adubação em linha ${ }^{2}$} \\
\hline Pá de corte & 9,7 & 6,4 & 32,6 & 17,2 & 13,0 \\
\hline Trado de rosca & 12,0 & 8,4 & 66,6 & 33,4 & 16,7 \\
\hline
\end{tabular}

${ }^{1}$ sistema plantio direto com nove anos de cultivo. ${ }^{2}$ Sistema plantio direto com doze anos de cultivo.

potássio, respectivamente para o erro $(e)$ em torno da média de 20 e $10 \%$. Esses resultados são semelhantes aos encontrados por SCHLINDWEIN $\&$ ANGHINONI (2000).

\section{CONCLUSÕES}

1) Amostragens de solo com pá de corte no sistema plantio direto, com tamanho de fatia maior do que $5 / 10 \mathrm{~cm}$ (espessura/largura) não representam ganhos substanciais na redução da variabilidade de fertilidade do solo em lavouras com adubação a lanço.

2) Amostragens de solo com pá de corte com 5/10cm (espessura/largura) em lavouras com adubação a lanço, apresentam eficiência semelhante à de amostragens com $5 \mathrm{~cm} /$ largura das entrelinhas com adubação em linha no sistema plantio direto.

3) O número de subamostras retirado com pá de corte, conforme procedimento especificado na conclusão anterior, na faixa de 10 a 20 pontos, recomendado pela COMISSÃO... (1995) para o sistema convencional de cultivo, implica admitir um erro de $20 \%$ em relação à média.

4) O uso do trado de rosca requer a coleta de um número muito elevado de subamostras no sistema plantio direto, especialmente nas lavouras com adubação em linha e pode induzir a recomendações mais elevadas de adubos e corretivos pela perda da camada superficial do solo no momento da coleta.

\section{AGRADECIMENTOS}

Aos pesquisadores José Eloir Denardin e Rainoldo Alberto Kochhann da Embrapa Trigo e aos agricultores Jorge Jovanella e Fernando Kraedy por disponibilizar as áreas para a coleta das amostras e por fornecer as respectivas informações.

\section{REFERÊNCIAS BIBLIOGRÁFICAS}

ANGHINONI, I., SALET, R.L. Amostragem do solo e as recomendações de adubação e calagem no sistema plantio direto. In: NUERNBERG, N. J. (ed.). Conceitos e fundamentos do sistema plantio direto. Lages : SBCS/Núcleo Regional Sul, 1998. p.27-52.

COMISSÃO DE FERTILIDADE DO SOLO - RS/SC. Recomendações de adubação e calagem para os estados do Rio Grande do Sul e Santa Catarina. 3.ed. Passo Fundo : SBCS - Núcleo Regional Sul/EMBRAPA/CNPT, 1995. 224 p.

Tabela 3 - Número ${ }^{(1)}$ de subamostras para os atributos de fertilidade do solos, Latossolo Vermelho Distroférrico, amostrados com diferentes equipamentos em lavouras comerciais do sistema plantio direto com diferentes modos de adubação e probabilidade de erro em torno da média.

\begin{tabular}{lcccccccccc}
\hline $\begin{array}{l}\text { Probabilidade } \\
\text { de erro }(e)^{1}\end{array}$ & \multicolumn{2}{c}{ pH água } & \multicolumn{2}{c}{ Índice SMP } & \multicolumn{2}{c}{ P Mehlich-I } & & \multicolumn{2}{c}{ K Mehlich-I } & Mat.Org. \\
\cline { 2 - 5 } & Pá & Trado & Pá & Trado & Pá & Trado & Pá & Trado & Pá & Trado \\
\hline
\end{tabular}

$\%$

\begin{tabular}{|c|c|c|c|c|c|c|c|c|c|c|}
\hline \multicolumn{11}{|c|}{ Adubação a lanço ${ }^{2}$} \\
\hline 20 & 1 & 1 & 1 & 1 & 11 & 23 & 3 & 5 & 2 & 2 \\
\hline 10 & 1 & 1 & 1 & 1 & 45 & 92 & 13 & 19 & 7 & 9 \\
\hline \multicolumn{11}{|c|}{ Adubação em linha ${ }^{3}$} \\
\hline 20 & 1 & 1 & 1 & 1 & 11 & 46 & 3 & 11 & 2 & 3 \\
\hline 10 & 4 & 6 & 2 & 3 & 44 & 183 & 13 & 46 & 7 & 11 \\
\hline
\end{tabular}

${ }^{1}$ Calculado pela equação $n=\left[\left(t_{\alpha} \cdot C V\right) / e\right]^{2}$, onde: $n$ é o número de subamostras; $C V$ é o coeficiente de variação; $t$ é o valor da tabela do teste t para $\alpha=0,05$ e $e=10$ e $20 \%$ em relação à média.

${ }^{2}$ Sistema plantio direto com nove anos de cultivo. ${ }^{3}$ Sistema plantio direto com doze anos de cultivo.

Ciência Rural, v. 32, n. 6, 2002. 
ELTZ, F.L.P., PEIXOTO, R.T.G., JASTER F. Efeitos de sistemas de preparo do solo nas propriedades físicas e químicas de um latossolo bruno álico. R Bras Ci Solo, v.13, p.259-267, 1989

JAMES, D.W., WELLS, K.L. Soil sample collection and handling: technique based on source and degree of field variability. 3.ed. In: WESTERMAN, R.L. (Ed.). Soil testing and plant analysis. Madison: Soil Science Society of America, 1990. p.25-44.

KLEPKER, D., ANGHINONI, I. Phosphate uptake and corn root distribuition as affected by fertilizer placement and soil tillage. Agronomy-Trends in Agril Sci, v.1, p.111-115, 1993.

KLEPKER, D., ANGHINONI, I. Características físicas e químicas do solo afetadas por métodos de preparo e modos de adubação. R Bras Ci Solo, v.19, p.395-401, 1995.

KRAY, C.H., SALET, R.L., ANGHINONI, I. Variabilidade horizontal e amostragem dirigida do solo no sistema plantio direto. In: SALÃO DE INICIAÇÃO CIENTÍFICA, 9; FEIRA DE INICIAÇÃO CIENTÍFICA, 4, 1997, Porto Alegre, RS. Resumos... Porto: Alegre : Universidade Federal do Rio Grande do Sul, 1997. p.72.
SALET, L.R., KRAY, C.H., FORNARI, T.G., $\boldsymbol{e} \boldsymbol{t} \boldsymbol{a l}$. Variabilidade horizontal e amostragem de solo no sistema de plantio direto. In: REUNIÃO SUL BRASILEIRA DE CIÊNCIA DO SOLO, 1, 1996, Lages, SC. Resumos Expandidos... Lages : NRS/SBCS, 1996. p.74-76.

SANTOS, H.L., VASCONCELLOS, C.A. Determinação do número de amostras de solo para análise química em diferentes condições de manejo. R Bras Ci Solo, v.11, p.97$100,1987$.

SCHLINDWEIN, J.A., ANGHINONI, I. Variabilidade horizontal de atributos de fertilidade e amostragem do solo no sistema plantio direto. R Bras Ci Solo, v.24, p.85-91, 2000.

SOUZA, L. S. Variabilidade espacial do solo em sistemas de manejo. Porto Alegre, 1992. 102p. Tese (Doutorado em Ciência do Solo) - Programa de Pós-graduação em Agronomia, Universidade Federal do Rio Grande do Sul, Porto Alegre, 1992.

TEDESCO, M.J., GIANELLO, C., BISSANI, C.A., et al. Análise de solo, plantas e outros materiais. 2.ed. Porto Alegre: Universidade Federal do Rio Grande do Sul, 1995. 147p. (Boletim Técnico, 5). 